\title{
A Neuropsychological Study of Fact Memory and Source Amnesia
}

\author{
Arthur P. Shimamura and Larry R. Squire \\ Veterans Administration Medical Center, San Diego, and Department of Psychiatry, \\ School of Medicine, University of California, San Diego
}

\begin{abstract}
We investigated the ability of amnesic patients to learn new facts (e.g., Angel Falls is located in Venezuela) and also to remember where and when the facts were learned (i.e., source memory). To assess the susceptibility of fact and source memory to retrograde amnesia, patients prescribed electroconvulsive therapy were presented facts prior to the first treatment and were tested after their second treatment. All amnesic patients exhibited marked fact memory impairment. In addition, some amnesic patients exhibited source amnesia (i.e., they recalled a few facts but then could not remember where or when those facts had been learned). Source amnesia was unrelated to the severity of the memory deficit itsclf, because patients who exhibited source amnesia recalled as many facts as the patients who did not. These results show that the deficit in amnesia includes an impairment in acquiring and retaining new facts. Source amnesia can also occur, but it is dissociable from impaired recall and recognition and appears to reflect difficulty in remembering the specific context in which information is acquired. The findings are discussed in terms of their significance for how memory is organized.
\end{abstract}

In the typical memory test, subjects are asked to remember information learned in a specific context or episode (e.g., "Can you remember which of these words were the ones I just showed you?" or "Did you see this picture 5 minutes ago?"). It is possible, however, to construct memory tests that do not make explicit reference to the context in which information was learned. For example, tests of newly learned facts (e.g., Where is Angel Falls located?) require subjects to remember only the fact itself; it is not necessary to remember when or where it was learned. Many everyday situations involve this kind of fact learning, in that it is often important to remember what was said rather than when or where it was said.

The distinction between memory for content and memory for context has been useful for understanding the organization of memory. One of the best descriptions of this distinction has been developed by Tulving $(1972,1983)$, who has cogently argued for a distinction between semantic and episodic memory. Neurobehavioral data could provide critical evidence for such a distinction (Tulving, 1986). Indeed, some have argued that this distinction is prominently reflected in the organization of brain systems. One view is that amnesia reflects a selective deficit of episodic memory (Cermak, 1984; Kinsbourne \& Wood, 1975, 1982; for a review, see Schacter \& Tulving, 1982).

This research was supported by National Research Service Award MH08992 from the National Institute of Mental Health to Arthur P. Shimamura, the Medical Research Service of the Veterans Administration, the Office of Naval Research, and National Institute of Mental Health Grant MH24600 to Larry R. Squire.

We thank Joyce Zouzounis, Armand Bernheim. Patty Feldstein, Kim Rivero-Frink, and Deborah Rosenthal for research assistance and Dr. Stuart Zola-Morgan for helpful comments on earlier drafts.

Correspondence concerning this article should be addressed to Arthur P. Shimamura, Department of Psychiatry (M-003), University of California, San Diego, La Jolla, California 92093.
Another, similar view is that amnesic patients have a disproportionately large deficit in remembering contextual information (Hirst, 1982; Huppert \& Piercy, 1978; for a review, sec Mayes, Meudell, \& Pickering, 1985).

In light of these ideas about amnesia, one might suppose that fact learning should be spared in amnesia or be less affected than the ability to learn contextual information because tests of fact learning do not require subjects to recollect the learning episode explicitly. Only a few studies have explored this possibility. Wood, Ebert, and Kinsbourne (1982) described a patient who became amnesic at the age of 9 years. This patient was able to progress in school work, albeit slowly, during the years following the onset of amnesia. This finding suggests that some semantic memory could be acquired, but not in a normal fashion (see also, Brown, Wood, \& Felton, 1986; Ostergaard, in press). Cermak and O'Connor (1983) examined a patient who had received a masters degree in physics and had become president of an optical firm prior to the onset of amnesia. Nevertheless, this amnesic patient was unable to add new factual knowledge related to his previous expertise, despite encouragement and suggestions to use mnemonic techniques.

In another study, Gabrieli, Cohen, and Corkin (1983) attempted to teach new vocabulary words to H.M., the wellknown amnesic patient who has been severely amnesic since 1953. The words had been added to the dictionary after 1966 . After training, H.M. was impaired on recall and recognition tests involving the definitions of the new vocabulary words. Moreover, he performed at chance in a lexical decision task for the words that had been studied but whose meaning he did not know. Thus, asking factual questions without making explicit reference to the learning episode did not seem to make the amnesic patient's task noticeably easier. Taken together, the findings from these case studies suggest that amnesic patients do have difficulty acquiring new factual information. However, it is not clear whether the difficulty in learning new facts is just as 
severe or less severe than the difficulty in learning new contextual information.

One line of recent work suggests that tests of factual knowledge might be advantageous for amnesic patients. Specifically, amnesic patients can successfully learn some tasks that are "implicit" and that can be accomplished without reference to the context in which the knowledge was acquired. For example, perceptual and motor skills, such as mirror reading and rotor pursuit, are preserved in amnesia (see Brooks \& Baddeley, 1976; Cermak, Lewis, Butters, \& Goodglass, 1973; Cohen \& Squire, 1980; Corkin, 1968; Milner, 1962). These skills are often retained for months after learning, even though amnesic patients have poor conscious recollection of having performed the skill or having seen the testing apparatus. Further evidence for the presence of implicit memory ability in amnesia comes from the finding of intact priming effects in amnesia (e.g., Graf, Squire, \& Mandler, 1984; Graf \& Schacter, 1985; Jacoby \& Witherspoon, 1982; Shimamura \& Squire, 1984; for a review, see Shimamura, 1986). In all of these tests, good performance does not require explicit memory for where, when, or even how information was learned. That is, performance is "context free" (Kinsbourne \& Wood, 1982), and episodic memory need not be available in order to do well. Are tests of factual knowledge related to implicit memory tests?

One important difference exists between tests of skills and priming, on the one hand, and tests of fact knowledge on the other. Skill learning and priming effects are exhibited purely in a subject's performance. That is, subjects can perform without any conscious awareness that their memory is being tested. In such tasks, subjects are simply asked to read text, complete word beginnings, or free associate to cue words. The only memory requirement is that linguistic knowledge (i.e., lexical memory) be intact. It is not necessary to recollect any facts or episodes about the event that led to altered performance. By contrast, in tests of fact memory, subjects may not need to remember where or when the fact was learned, but they know their memory is being tested, and they still must consciously recollect the fact itself. For instance, the experimenter can ask a subject, "Where is Angel Falls located?" without stating or implying that the answer had been presented a few minutes ago. Yet, memory for the fact itself is explicitly requested. This feature of fact memory tests distinguishes them from tests of skills or priming.

One view of amnesia and the organization of memory takes into account these differences between skill learning, priming, and fact memory. Amnesia has been described as a dissociation between declarative and procedural memory rather than as a dissociation between episodic and semantic memory (Cohen, 1984; Cohen \& Squire, 1980; Squire, 1987; Squire \& Cohen, 1984). Declarative memory includes explicit memory for facts, data, and the episodes accumulated throughout one's life. Procedural memory includes motor and cognitive skill learning, simple classical conditioning, and possibly priming effects. Priming can be taken as an example of procedural memory, because it relies on changes in the facility for performing particular cognitive operations within lexical memory (Crowder, 1985; Shimamura, 1986; Tulving, 1983). By this view, amnesic patients exhibit an impaired ability to acquire declarative memory, but they exhibit an intact ability to acquire procedural memory. There is a growing consensus that procedural memory is spared in amnesia and that this kind of knowledge is distinct from both episodic memory and fact memory (Baddeley, 1984; Tulving, 1983; Squire \& Cohen, 1984).

These considerations provide a rationale for why fact memory might be impaired in amnesia, whereas skills and priming are spared. Amnesia produces an impairment in the ability to acquire declarative memory (i.e., both episodic and semantic memory), not a deficit limited to episodic or contextual memory. Yet the declarative--procedural and episodic-semantic distinctions need not be mutually exclusive classifications of memory organization. For example, one possibility is that all amnesic patients exhibit impaired declarative memory, and that some amnesic patients exhibit an additional deficit in episodic or contextual memory.

Schacter, Harbluk, and McLachlan (1984) recently provided evidence in favor of this idea. They found an impairment of episodic memory in memory-impaired patients, which was disproportionately large compared to the deficit in fact memory. They presented made-up facts (e.g., Bob Hope's father was a fireman) to a mixed group of memory-impaired patients (e.g., patients with Alzheimer's disease, head injury, encephalitis) and then gave a recall test directly after presentation of this information. If a fact was recalled, patients were asked how they had acquired the recalled information. Frequently, patients recalled a fact but stated that it was learned prior to the experimental session, even though it had actually been learned a few minutes earlier. That is, they exhibited source amnesia (see Evans \& Thorn, 1966). Source amnesia could not be attributed simply to poor memory because control subjects, whose fact memory performance was matched to that of amnesic patients by testing them after a 1-week delay, exhibited few source errors. Moreover, in the amnesic patients, source memory performance was correlated with performance on tests sensitive to frontal lobe pathology.

The available data raise several questions about the ability of amnesic patients to learn and retain new factual information. Are there conditions in which fact learning is preserved in amnesia? Is source amnesia a typical feature of human amnesia or does it occur only in certain patients, for example, those who because of conditions like Alzheimer's disease or head injury are likely to have relatively widespread brain damage? Alternatively, do only the most severely amnesic patients exhibit source amnesia? What is the relation between the severity of source amnesia and the severity of fact memory impairment?

In three experiments, we tested the ability of amnesic patients to learn new factual information and to report when and where a correctly recalled fact was last heard (i.e., source memory). In Experiment 1, we tested fact and source memory in an intentional learning paradigm similar to the one used by Schacter et al. (1984). In Experiment 2, we used an incidental learning paradigm. Finally, in Experiment 3 we investigated both fact and source memory when learning occurred prior to the onset of amnesia and was tested after its onset. In that experiment, patients who were prescribed electroconvulsive therapy (ECT) were presented facts prior to the first treatment, and they were given tests of fact and source memory following their second treatment. 


\section{Experiment 1}

We presented the answers to facts that could not be recalled and then tested fact recall and recognition after a 2-hr delay. Source memory was tested by asking subjects to report the last time a correctly recalled fact was encountered. If a subject claimed that a fact was learned from an outside source, even though it was presented during the study phase, then a source error was recorded. The design of this study was similar to the study of Schacter et al. (1984), but there were four important differences between our study and Schacter et al.'s. First, we studied patients with Korsakoff's syndrome, patients with amnesia due to an anoxic or ischemic event, and case N.A. Second, we used actual facts rather than made-up facts. Third, we used a 2-hr retention interval rather than an interval of several minutes. Finally, in this study one experimenter presented all the facts to each patient, and subjects attempted to discriminate facts learned during the study session from facts learned at some earlier time. Schacter et al. (1984) used this measure and also asked subjects to discriminate whether facts presented during the study session had been read to them by a man or a woman.

To test the possibility that poor source memory could result from weak fact memory, we assessed source memory for a group of control subjects tested after a 1-week retention interval. Fact memory performance for this group of "delayed" control subjects matched the performance of amnesic patients tested after a 2-hr delay. If source errors occur as a result of poor memory, then control subjects tested under weak memory conditions should exhibit as many source errors as amnesic patients. Alternatively, if source errors are unique to amnesic patients then it can be argued that contextual or episodic memory is disproportionately impaired in these patients.

\section{Method}

\section{Subjects}

Amnesic patients. We tested a group of 11 amnesic patients: 7 with alcoholic Korsakoff's syndrome, 2 with amnesia due to an anoxic episode, 1 with amnesia due to an ischemic episode, and case N.A. The patients with Korsakoff's syndrome consisted of 5 men and 2 women living in supervised facilities in San Diego County. These patients have been studied as a group for several years (Graf et al., 1984; Shimamura \& Squire, 1986; Squire, 1982).

Of the 2 patients with amnesia that was due to an anoxic episode, 1 became amnesic in 1976 following a cardiac arrest (case A.B.), and another became amnesic in 1984 when respiratory arrest occurred during an epileptic seizure (case L.M.). The patient with amnesia due to ischemia became amnesic in 1983 following a period of hypotension that occurred during major surgery (case G.D.). Case N.A. has been severely amnesic for verbal material since 1960 when he sustained a stab wound to the brain with a miniature fencing foil (see Kaushall, Zetin, \& Squire, 1981; Teuber, Milner, \& Vaughan, 1968).

The 11 amnesic patients averaged 49.7 years of age, had 12.5 years of education, and had an average Wechsler Adult Intelligence Scale (WAIS) IQ score of 108.5. Their average Wechsler Memory Scale (WMS) score was 83.0, and the average WAIS-WMS difference was 25.5 (range $=16-$ 39). In normal subjects, the WMS is equal to WAIS. For the 11 amnesic patients, average scores for immediate and delayed recall $(12 \mathrm{~min})$ of a short prose passage was 5.0 and 0 segments, respectively $(21$ segments total). Average scores for copy and delayed recall $(12 \mathrm{~min})$ of a complex diagram were 29.4 and 6.0 segments, respectively ( 36 segments total). Paired-associate memory of 10 unrelated noun-noun pairs on each of three successive trials was $0.6,0.5$, and 1.4 . Neuropsychological screening and independent neurological examination indicated that memory impairment was the only remarkable deficit of higher cortical function. All patients could draw a cube and a house in perspective, and none had aphasia or apraxia. For 10 of the 11 amnesic patients, more extensive neuropsychological assessment was obtained (see Squire \& Shimamura. 1986). In particular, these 10 amnesic patients averaged 132.5 points out of a possible 144 points on the Dementia Rating Scale (Coblentz, Mattis, Zingesser, Kasoff, \& Katzman, 1973), losing most of their points on the memory subportion of the test. Also, on 5 successive study-test trials these patients averaged 3.6, 4.3,4.8,4.5 for free recall of 15 nouns and averaged $21.9,24.7,25.0,26.0,26.9$ for yes-no recognition of 15 previously presented nouns and 15 new nouns.

Alcoholic control subjects. We tested 17 alcoholic control subjects. These subjects had an average drinking history of 22.1 years but had abstained from alcohol for an average of 17.1 weeks prior to participating in the experiment. They averaged 51.4 years of age, had 13.5 years of education, and had a WAIS-Revised subtest score of 18.9 for information ( 18.9 for amnesic patients) and 47.2 for vocabulary ( 49.9 for amnesic patients). Their scores for immediate and delayed recall $(12 \mathrm{~min}$ ) of a short prose passage averaged 7.8 and 6.8 segments, respectively. We divided these alcoholic subjects into two groups. The first group ( 7 subjects) was tested after a 2 -hr retention interval just as the amnesic patients. The second group ( 10 subjects) was tested after a 7-day retention interval at a time when fact memory performance for this group matched that of the amnesic patients tested after a 2 -hr delay.

\section{Materials}

We compiled a list of 30 difficult general-information questions from Nelson and Narens (1980) and from reference books, and divided them into three equal sets of 10 questions each. The questions tapped obscure knowledge about a variety of topics including geography, sports, history, and entertainment (e.g., What is the name of the town through which Lady Godiva supposedly made her famous ride?). Two of the sets were presented as study material, and another set was used during the retention test to obtain a measure of baseline recall performance. These sets were rotated across study and baseline conditions so that every three subjects formed a completely counterbalanced group. Because subject groups were not numbered in multiples of three, we used only a partially counterbalanced design.

\section{Procedure}

Subjects were told that they would be given the answers to some general-information questions and that they should try to remember them. In order to ensure that the questions could not be recalled from prior knowledge, we began by asking subjects to answer each question. If the answer to a question was known to a subject, it was discarded from the study set and replaced with one from a list of supplemental questions. If the answer to a question could not be correctly recalled, then the answer to the question was read by the experimenter as a factual statement (e.g., "The name of the town through which Lady Godiva supposedly made her famous ride is Coventry."). This procedure continued until the answers to 20 nonrecalled questions had been presented. Following this input phase, the answers to the 20 questions were presented for study a second time but in a different order. All questions and answers were presented orally. Subjects were tested individually.

After a 2-hr retention interval, tests of fact recall, source recall and fact recognition memory were given. During the test phase, no reference was made to the previous study phase; subjects were simply asked to answer some general-information questions. We tested memory for the 
20 facts that had been presented at study and also tested knowledge of 10 difficult (baseline) facts and 10 easy facts, which had not been presented at study. The easy facts were included so that when subjects were asked to identify the source of the remembered information some of it would have originated outside the experimental situation. These 20 new fact questions were intermixed with the 20 questions about facts that had been studied.

If a subject correctly recalled a fact, we asked, "When was the last time you heard this information?" The experimenter recorded the approximate time and place in which the fact was last heard. If a subject claimed that a recalled fact was learned from an outside source, even though it was presented during the study phase, then a source error was recorded. We called these errors extraexperimental source errors (after Schacter et al., 1984). We scored extraexperimental source errors by calculating the number of such errors out of the total number of study facts recalled. A different type of source error oocurred when subjects claimed that a correctly recalled fact was one they had learned during the study phase, even though it had never been presented before. This type of source error was called an experimental source error, and it could potentialiy be committed for any of the 20 new questions (10 difficult questions +10 easy questions) that were correctly recalled. Following the tests of fact and source recall, we gave an 8-altemative forcedchoice recognition test for the 20 facts presented during the study phase and the 20 nonpresented facts

In addition to the amnesic and alcoholic groups tested after a 2-hr retention inter val, we tested another group of alcoholic subjects after a 7 -day retention interval. Other than the length of the retention interval, this control group was tested in exactly the same way as the other two groups. This additional control group matched the amnesic patients on fact memory performance and allowed us to determine if source errors can occur simply as a consequence of poor fact memory.

\section{Results and Discussion}

Amnesic patients exhibited impaired fact memory as measured by tests of both recall, $(16)=4.3, p<.01$ (see Figure 1), and recognition, $t(16)=3.6, p<.01$. On tests of fact recall, amnesic patients averaged $31 \%$ correct and alcoholic subjects averaged $74 \%$ correct (baseline $=0 \%$ ). On tests of fact recognition, amnesic patients averaged $56 \%$ correct and alcoholic subjects averaged $91 \%$ correct (baseline for the two groups averaged $37 \%$ ). The baseline score was calculated by determining what percentage of the 10 difficult (nonpresented) items could be recognized, given that they could not be recalled. Recall performance for the 7 patients with Korsakoff's syndrome, for the 3 anoxic-ischemic patients, and for N.A. was 23\%, 43\%, and 50\% correct, respectively; and recognition performance was $52 \%$, $56 \%$, and $80 \%$ correct, respectively.

The finding of impaired fact learning in amnesia cannot be attributed to differences in prior knowledge of facts, because the amnesic patients and alcoholic subjects did not differ in their fact memory ability prior to the learning sessiom. Specifically, in the course of being presented 20 questions that they could not recall, amnesic patients answered 4.5 factual questions correctly, and alcoholic patients answered 3.7 questions. Moreover, during the retest, amnesic patients and alcoholic subjects performed similarly on the 20 new questions. For the 10 new easy questions and the 10 new difficult questions presented during the recall test but not during the study phase, amnesic patients recalled an average of 7.9 easy facts and 2.8 difficult facts (control subjects: 8,1 easy facts and 1.9 difficult facts).

The results also cannot be attributed to the fact that recall
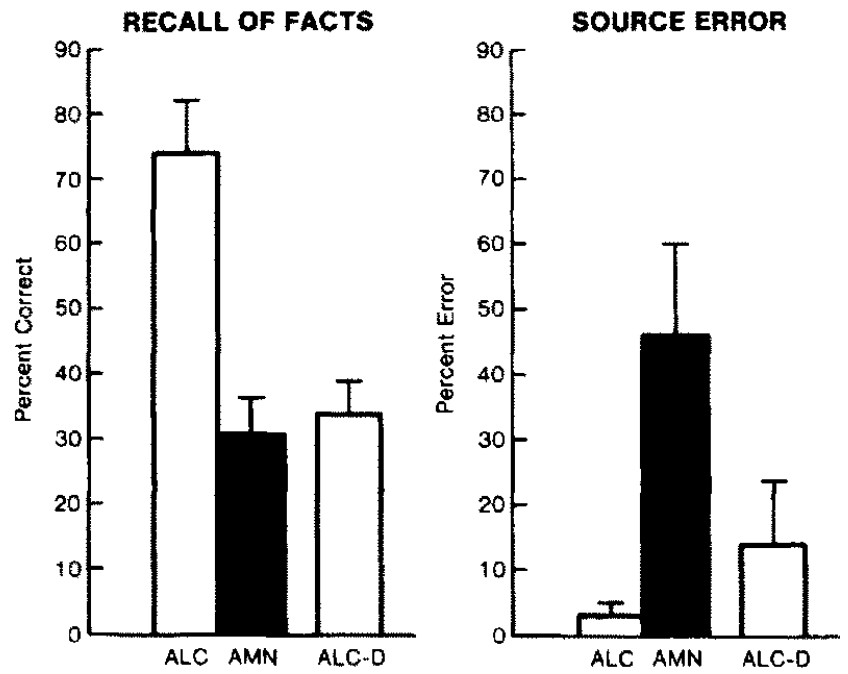

Figure 1. Recall of facts (lefi) and source memory performance (right) by amnesic patients ( $A M N$ ) and alcoholic control subjects ( $A L C$ ) tested after a 2-hr retention interval. (Delayed alcoholic subjects [ALC-D] were tested after a 7 -day retention interval. Error bars represent standard error of the mean.)

was assessed twice (once during the screening phase and again during the actual recall test). One could suppose that giving a second test trial might itself improve recall performance and that this improvement would occur more for control subjects than for amnesic patients. Because item fluctuations have been observed in recall tests of word lists (Nelson \& Macleod, 1974; Tulving, 1967), we presented 20 of the general-information questions used in this experiment to a different group of 6 alcoholic subjects and asked them to recall the information on two occasions, $2 \mathrm{hr}$ apart. Recall performance was $11 \%$ and $12 \%$ correct on the first and second trials, respectively. Thus, amnesic patients exhibited a true impairment in fact learning.

Source memory was also impaired in amnesic patients (see Figure 1). The patients committed an average of $45 \%$ extraexperimental source errors: that is, patients often failed to remember that a correctly recalled fact was one that was learned $2 \mathrm{hr}$ before. Alcoholic subjects averaged only $3 \%$ source errors. Importantly, source memory impairment was variable across amnesic patients. Four amnesic patients exhibited $100 \%$ extraexperimental source errors, 2 patients made about $40 \%$ errors, 1 patient made $10 \%$ errors, and 4 patients did not make any source errors. The 4 patients who committed $100 \%$ source errors were 3 patients with Korsakoff's syndrome and a patient who became amnesic following a cardiac arrest (A.B.). During the test session, these 4 patients never mentioned the previous study session. The 4 patients who did not commit any source errors were 4 patients with Korsakoff's syndrome.

Thus, amnesic patients were able to remember some facts, though they could often not recall the context within which those facts were learned. It was clear that patients were not simply responding randomly to the source questions. They were able to identify correctly those facts that were never presented during the experimental setting. Thus, in the case of the 20 new questions that could be correctly answered, experimental 
source errors were never made. The patients were always accurate in stating that these facts were encountered prior to the study phase.

Interestingly, source memory impairment was not related to fact memory impairment. The 4 amnesic patients who made $100 \%$ source errors remembered about the same number of facts as the 4 patients who made $0 \%$ source errors. Specifically, the 4 patients who made $100 \%$ source errors recalled $31.7 \%$ facts and recognized $46.2 \%$ facts, whereas the 4 patients who made $0 \%$ source errors recalled $25.0 \%$ facts and recognized $47.5 \%$ facts. Furthermore, the group of delayed alcoholic subjects committed only $14 \%$ source errors (see Figure 1), despite the fact that their recall $(34 \%)$ and recognition $(67 \%)$ performance matched the fact memory performance of the amnesic patients. Thus, the source memory impairment exhibited by some amnesic patients could not be explained as a consequence of their poor fact memory.

\section{Experiment 2}

In this experiment we evaluated the ability of amnesic patients to learn factual information incidentally. It seemed possible that the intentional learning instructions in the previous experiment gave control subjects an advantage over amnesic patients because they could engage in extensive elaborative encoding. Yet, much of the information that we learn in daily life is learned incidentally. Perhaps fact learning would be preserved in amnesic patients if information were learned incidentally.

We also assessed source memory. This measure provided a replication of the source memory impairment observed in Experiment 1 with the same amnesic patients. In that experiment, source memory performance was variable: some patients exhibited source amnesia and some did not. This experiment provided a way to determine if source memory performance is a consistent phenomenon within individual amnesic patients.

\section{Method}

\section{Subjects}

Amnesic patients. We tested 10 of the 11 patients described in Experiment I; 1 patient with Korsakoff's syndrome was not available for testing.

Alcoholic control subjects. We tested 14 new alcoholic control subjects. These subjects had an average drinking history of 22.8 years but had abstained from alcohol for an average of 30.8 weeks prior to participating in the experiment. They averaged 52.1 years of age, had 12.2 years of education, and had a WAIS subtest score of 18.2 for information (18.9 for amnesic patients) and 42.1 for vocabulary (42.9 for amnesic patients). We divided these alcoholic subjects into two groups. The first group ( 8 subjects) was tested after a 5-min delay, just as the amnesic patients. The second group ( 6 subjects) was tested after a 2-hr delay in order to assess source memory in subjects whose fact memory performance matched that of the amnesic patients.

\section{Materials}

Thirty difficult trivia facts (e.g., The last name of Lucy and Linus in the comic strip, "Peanuts" is Van Pelt) were obtained from encyclopedias and popular books on trivia and printed individually on index cards. None of these facts had been used in the previous experiment The facts were divided into two sets of 15 each. Each set contained three facts from each of five categories: (a) books and comics, (b) movies and plays, (c) history, (d) geography, and (e) sports. One set was presented for study and another set was used to assess baseline recall and recognition performance. The two sets were counterbalanced across study and baseline conditions.

\section{Procedure}

This task required subjects to read and encode 15 trivia facts, without any instructions to learn or remember them. Cue cards showing the five categories were placed in front of the subject. Subjects were asked to read each fact and place it next to the appropriate category name. The task was self-paced. After sorting all 15 facts, subjects sorted the facts a second time, reading the facts aloud and placing them in a category. For the second presentation, the category cue cards were rearranged, and the facts were presented in a different order.

After a 5-min retention interval, we tested fact recall, source recall, and fact recognition for the 15 study facts, 15 new facts that had not been presented, and 4 new easy facts. This test phase was identical to the procedure used in Experiment 1. During the recall test, if a subject correctly recalled a fact, we asked, "When was the last time you heard this fact?" The experimenter recorded the approximate time and place in which the fact was last heard.

A second group of alcoholic subjects was tested after a 2-hr delay. This additional control group was matched to the amnesic patients on incidental fact memory performance and as in Experiment 1 it provided a test of the possibility that source errors are related to poor fact memory.

\section{Results and Discussion}

We obtained baseline recall and recognition rates from each subject by including 15 facts that had been used as study material for other subjects. Baseline performance was not significantly different across amnesic patients, alcoholic controls, and delayed alcoholic controls: baseline recall, $F(2,21)=1.0, p=$ .37 ; baseline recognition, $F(2,21)=1.1, p=.36$. Because of the incidental nature of the study task, we could not screen the questions for prior recall ability. In order to evaluate fact recall memory statistically, we subtracted each subject's recall performance for the 15 baseline facts from his or her performance for the 15 studied facts. We used the same measure to assess recognition performance.

Even when facts were presented incidentally, amnesic patients exhibited impaired fact memory (see Figure 2). Compared with alcoholic control subjects, amnesic patients exhibited impaired fact recall, $t(16)=2.15, p<.05$, and impaired recognition, $t(16)=3.28, p<.01$. Alcoholic subjects recalled $43 \%$ correct facts (baseline $=8 \%$ ) and recognized $78 \%$ correct facts (baseline $=32 \%$ ). As a group, the amnesic patients averaged $32 \%$ recall (baseline $=14 \%$ ) and $54 \%$ recognition (baseline $=42 \%$ ). Recall and recognition performance across etiologies were as follows: $24 \%$ and $52 \%$ correct facts for six patients with Korsakoff's syndrome, $35 \%$ and $53 \%$ facts correct for three anoxic-ischemic patients, and $60 \%$ and $67 \%$ facts correct for N.A. Fact memory performance by alcoholic subjects tested after a 2 -hr retention interval was nearly the same as amnesic patients tested after a 5-min retention interval. Specifically, de- 

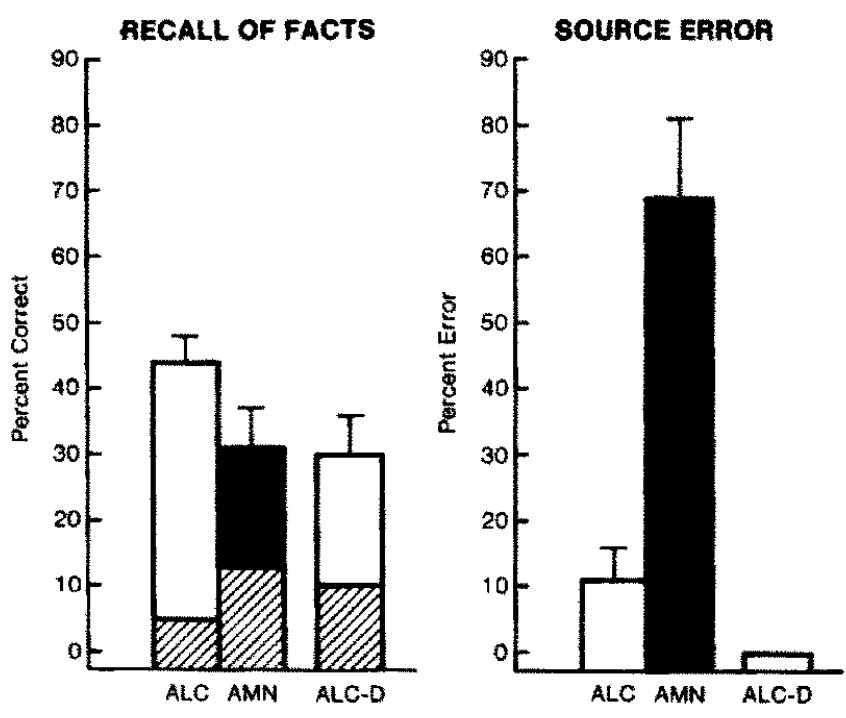

Figure 2. Recall of facts after incidental learning (lef) and source memory performance (right) by amnesic patients (AMN) and alcoholic control subjects (ALC) tested after a 5-min retention interval. (Baseline recall rates are shown below recall performance [hatched area]. Delayed alcoholic subjects $[A L C$-D $]$ were tested after a 2-hr retention interval. Error bars represent standard error of the mean.)

layed alcoholic subjects recalled $30 \%$ correct facts (baseline $=$ $10 \%$ ) and recognized $54 \%$ correct facts (baseline $=36 \%$ ).

Source memory was also impaired in amnesic patients (see Figure 2). Amnesic patients committed an average of $69 \%$ extraexperimental source errors, somewhat more than the numher of errors committed by these same patients in Experiment 1. One patient with Korsakoff's syndrome was excluded from this analysis because she did not correctly recall any facts and therefore did not have a chance to exhibit source errors (her fact recognition score was 53\%). Alcoholic subjects tested after a 5-min delay averaged only $11 \%$ source errors, and none of the delayed alcoholic subjects tested after a 2-hr delay committed any extraexperimental source errors. As in Experiment 1 . source memory impairment was variable among patients. However, the 4 amnesic patients who committed $100 \%$ extraexperimental source errors in Experiment 1 also committed $100 \%$ source errors in this experiment. One additional patient with Korsakoff's syndrome who had committed 0 os source errors in Experiment 1 committed $100 \%$ errors in this experiment, but that score was based on only one item. The other 4 amnesic patients, who averaged $23.2 \%$ source errors in Experiment 1, averaged $30.5 \%$ source errors in this experiment. Thus, even though source memory impairment was variable across patients, it was relatively consistent within patients in two separate experiments. Experimental source errors (i.e., stating that a fact was presented when actually it was never presented before) were low in all groups (amnesic patients $=11 \%$ errors; alcoholic subjects $=0 \%$ errors; delayed subjects $=3 \%$ errors).

As in the previous experiment, source memory impairment was not related to fact memory ability. The 4 patients who made $100 \%$ source errors, in both this experiment and the previous experiment, exhibited about the same fact recall memory score as the $\mathbf{4}$ patients who made the fewest source errors (average $=$
$23.5 \%$ source errors). Specifically, the 4 patients who made the most source errors recalled $36.5 \%$ facts and recognized $58.2 \%$ facts, whereas the 4 patients who made the fewest source errors recalled $40.0 \%$ facts and recognized $53.5 \%$ facts. Moreover, delayed control subjects, whose fact recall ( 30 \% facts) and recognition ( $54 \%$ facts) performance matched that of amnesic patients. did not exhibit any source errors. Thus, source memory impairment can be dissociated from the general fact memory impairment exhibited by amnesic patients.

\section{Experiment 3}

In the final experiment, we studied retrograde amnesia for recently learned facts. That is, we presented facts before the onset of amnesia and tested fact memory after its onset. We also assessed retrograde amnesia for source information. It has previously been shown that memory for a recently learned skill (i.e., reading mirror-reversed words) is spared following ECT, even when patients are taught the skill before and during the first 2 days of the treatment course (Squire, Cohen, \& Zouzounis, 1984). The skill survived ECT, but patients failed questions about the training experience itself. The present experiment tested whether fact learning, like skills, is spared following ECT or whether it is impaired like memory for recently occurring episodes and contextual information. We tested patients who were preseribed bilateral ECT, patients who were prescribed right unilateral ECT, and hospitalized depressed patients not receiving ECT. The study and test procedures were the same as those used in Experiment :.

\section{Method}

\section{Subjects}

Patients receiving bilateral electroconvuisive therapy. This group consisted of 9 inpatients (mean age $=44.3$ years; mean education $=13.0$ years) residing at one of five local hospitals. All patients had been prescribed bilateral ECT by their physicians for relief of depressive illness. Seven patients were treated with a monitored ECT apparatus (MECTA) machine, and two were treated with a Mederafi B-24 device. Electrode placement was bitemporal.

Patients receiving right unilateral ECT. This group consisted of 8 inpatients ( mean age $=36.3$ years; mean education $=13.6$ years) residing at six local hospitals. All had been prescribed right unilateral ECT by their physicians for relief of depressive illness. Six patients were treated with a MECTA machine and two were treated with a Medcraft B-24 device. Right unilateral ECT was given in the same manner as bilateral ECT, except that both electrodes were positioned over the right side of the head in a frontal-parietal or frontal-temporal configuration.

Depressed potients. This group consisted of 10 inpatients (mean age $=43.5$ years; mean education $=12.1$ years) with the clinical diagnosis of depression. These patients were inpatients at the same psychiatric hospitais as the patients prescribed ECT.

\section{Procedure}

Patients received treatment two or three times a week, as prescribed by their physicians. Anterograde and retrograde amnesia are prominent side effects of ECT (PTice, 1982: Squire, 1984). Following a posttreatment confusional period of about $30 \mathrm{~min}$, amnesia emerges as a relatively circumscribed disorder. The retrograde amnesia following ECT can be temporally limited, affecting information acquired a few years 

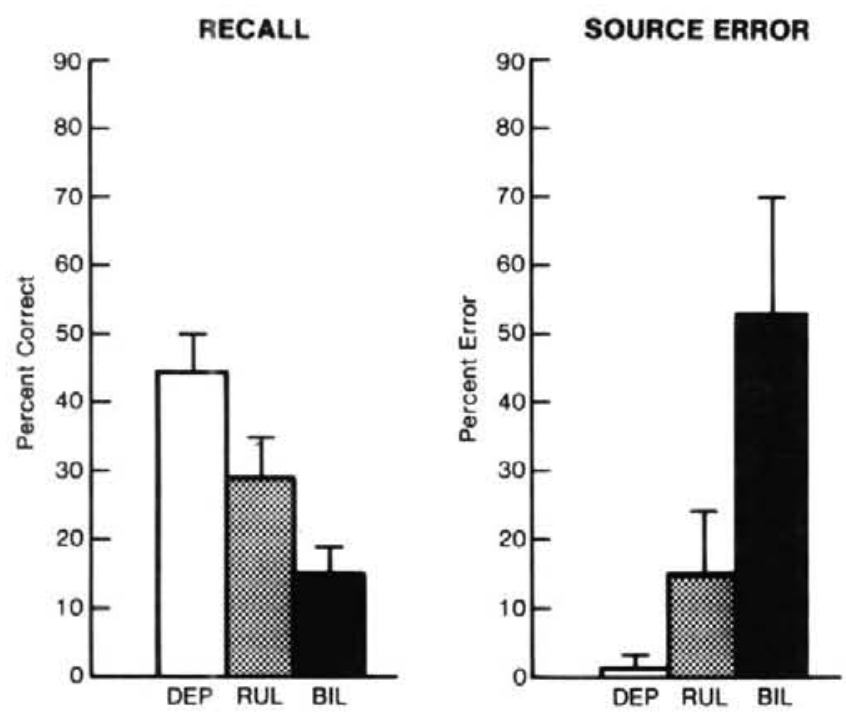

Figure 3. Fact recall (left) and source memory performance (right) for facts learned prior to bilateral ECT (BIL) or right unilateral ECT (RUL) and tested after the second treatment of the series. (Depressed patients [DEP] were tested after a comparable interval. Error bars represent standard error of the mean.)

prior to treatment and sparing more remote memory (Cohen \& Squire, 1981; Squire, Slater, \& Chace, 1975).

We presented facts one or two days before the first treatment and tested fact and source memory 6-10 hr after the second treatment. We used a similar retention interval for depressed patients. The mean retention intervals for patients receiving bilateral ECT, patients receiving right unilateral ECT, and depressed patients were 3.7 days, 3.1 days, and 3.6 days, respectively. Except for the retention interval, the procedure was exactly the same as the one used in Experiment 1. To summarize, subjects were given the answers to 20 questions that they could not recall. After the answers to all 20 questions were presented, the answers were presented for study a second time. Following the retention interval. fact recall, source recall, and fact recognition memory were tested for 20 study facts and 20 new facts ( 10 difficult facts +10 easy facts).

\section{Results and Discussion}

ECT produced retrograde amnesia for recently learned facts (see Figure 3). Patient groups differed significantly on tests of recall, $F(2,24)=4.9, M S_{\mathrm{e}}=406, p<.02$, and recognition, $F(2$, 24) $=6.4, M S_{\mathrm{e}}=452, p<.01$. Planned comparisons showed that the depressed patients recalled more facts than the patients prescribed bilateral ECT, $t(17)=3.0, p<.01$. Patients who were prescribed right unilateral ECT exhibited an intermediate level of performance, and their recall score did not differ significantly from either of the other two groups $(p>10)$. The same pattern of results was found for recognition memory performance (depressed patients $=75 \%$ correct; right unilateral ECT patients $=58 \%$ correct; bilateral ECT patients $=40 \%$ ). The depressed patients recognized significantly more facts than patients who were prescribed bilateral ECT, $t(17)=3.5, p<.01$, and the patients prescribed right unilateral ECT exhibited intermediate fact memory. Their performance was not significantly different from the other two groups: right unilateral ECT versus depressed patients, $t(16)=1.8, p=.09$; right unilateral ECT versus bilateral ECT patients, $t(15)=1.7, p=10$.
One might suppose that these three groups differed in degree of depression during the study phase or in general cognitive ability during the test phase and that such differences influenced memory performance. These possibilities seem unlikely. First, prior to ECT, retrieval of factual knowledge was comparable across groups as indicated by the number of questions that could be recalled during the initial screening phase (depressed patients, 2.7 questions; right unilateral ECT, 3.4 questions; bilateral ECT, 1.9 questions). Also, recall performance was similar for the 10 difficult, new questions presented during the test phase: Depressed patients recalled 0.7 facts, right unilateral ECT patients recalled 1.5 facts, and bilateral ECT patients recalled 1.6 facts. Moreover, recognition performance for these 10 new questions was similar across groups: $25 \%, 34 \%$, and $34 \%$ for depressed, right unilateral ECT, and bilateral ECT patients, respectively. Finally, performance was similar across groups on the 10 new easy questions (recall: $80 \%, 81 \%$, and $72 \%$ correct for depressed, right unilateral, and bilateral ECT patients, respectively; recognition: $93 \%, 94 \%$, and $88 \%$ ). Thus, the memory impairment associated with ECT selectively affected the retention of recently acquired factual information. It did not affect the ability to recall information that was already known at the time of the experiment and had presumably been acquired long ago.

As is shown in Figure 3, source memory was also different across subject groups, $F(2,21)=6.3, M S_{\mathrm{e}}=981, p<.01$. One bilateral ECT patient and 2 right unilateral ECT patients were excluded from this analysis because they failed to recall any study facts and therefore did not have an opportunity to exhibit source amnesia. Patients prescribed bilateral ECT made an average of 53\% extraexperimental source errors, whereas patients prescribed right unilateral ECT and depressed patients made only $15 \%$ and $1 \%$ source errors, respectively. Although bilateral ECT patients averaged $53 \%$ source errors, there was considerable variability across subjects. Four bilateral ECT patients made $100 \%$ source errors, 1 patient made $25 \%$ errors, and 3 patients did not make any source errors. As in the previous two experiments, the 5 patients who made source errors exhibited nearly the same level of fact recall and recognition memory ( $16 \%$ correct recall, $43 \%$ correct recognition) as the 3 patients who did not exhibit any source errors (18\% correct recall, $42 \%$ correct recognition).

Patients did not respond in a random or confused fashion to the source questions. They were able to identify correctly those facts that were never presented during the experimental setting. Thus, in the case of the questions that could be correctly answered but were never presented during the study phase, bilateral ECT patients, right unilateral ECT patients, and depressed patients were almost always accurate in stating that this information was learned prior to the study phase. In fact, only 1 patient (a right unilateral ECT patient) on one occasion incorrectly stated that an answer had been presented for study when it had not actually been presented.

\section{General Discussion}

Across a variety of study and test conditions, all of the amnesic patients exhibited impaired fact memory. Fact memory was impaired even when material was presented incidentally and 
then requested implicitly without making reference to the learning episode (Experiment 2). The finding with patients prescribed bilateral ECT (Experiment 3) demonstrated that fact memory was impaired when material was learned prior to the onset of amnesia and tested after its onset. This result can be contrasted with the finding that a mirror-reading skill was retained in a normal fashion when it was learned just prior to bilateral ECT and tested after treatment (Squire et al., 1984). Thus, retrograde amnesia spares recently acquired skills, but it affects recently acquired fact memory just as it affects contextual or episodic memory.

Memory for spatial-temporal context was disproportionately impaired in some, though not in all, amnesic patients. That is, some patients successfully recalled a few recently learned facts but also exhibited source amnesia: they did not recall the episode in which the facts were learned. This finding replicates the finding of Schacter et al. (1984). It also extends our understanding of source amnesia in several important ways. First, source amnesia was not restricted to those etiologies of memory impairment that produce relatively widespread cognitive impairment (e.g., Alzheimer's disease, head injury, encephalitis). Second, only some amnesic patients exhibited source amnesia. Nevertheless, the ones who exhibited the impairment did so consistently in two experiments. Third, source amnesia was unrelated to the severity of fact memory impairment. That is, patients who exhibited source amnesia recalled and recognized as many facts as the patients who did not. Fourth, source amnesia could not be explained as a dissociation specifically between recall ability and source memory because both fact recall and recognition memory were dissociated from source memory. Fifth, source amnesia was observed even when information was presented prior to the onset of amnesia resulting from ECT.

It is difficult to argue that source amnesia occurred because amnesic patients had been given repeated tests of fact memory and thus were more confused than control subjects about where or when they had learned the facts. First, these experiments were separated by 1-3 months. Second, if patients with source amnesia thought that they had been presented facts on some previous occasion, they could at least have reported that the information was learned during a prior experimental session. Yet, in the present experiments, amnesic patients never attributed the source to any prior experimental session. Instead, they attributed the fact to other sources, such as a newspaper article or a television show.

The finding of source amnesia appears to constitute a true dissociation between fact and context memory, or between semantic and episodic memory. That is, some amnesic patients exhibited a disproportionate impairment in remembering the spatial-temporal context in which facts were presented. In other words, their impairment in episodic memory was greater than would have been expected, given their level of fact memory performance. However, this dissociation was not observed in all patients. Some amnesic patients did not exhibit source amnesia, although they were just as impaired in fact memory as the patients who did exhibit source amnesia. Also, delayed control subjects whose fact memory performance was matched to the performance of amnesic patients did not exhibit source amnesia (see also Schacter et al., 1984). Source amnesia appears to represent a neurologically dissociable deficit that can occur in addition to impaired declarative memory. Source amnesia may be related to damage in brain regions other than the diencephalic and medial temporal areas that have been linked to amnesia (for a review, see Mair, Warrington, \& Weiskrantz, 1979; Mishkin, 1982; Squire \& Zola-Morgan, 1983). One possibility is that damage to frontal lobes produces source amnesia because these brain areas are involved in processing or storing spatial-temporal information (see Milner \& Petrides, 1984; Schacter, 1986; Squire, 1987). Indeed, Schacter et al. (1984) showed that source memory performance was correlated with performance on tests sensitive to frontal lobe pathology. We also found a positive, though nonsignificant, rank-order correlation between source memory performance (combined scores from Experiments 1 and 2 ) and performance on tests sensitive to frontal lobe dysfunction $\left(r_{\mathrm{s}}=.40\right)$. Thus, source amnesia could depend on frontal lobe pathology, which occurs in some patients, whereas the anterograde amnesia common to all patients is related to medial temporal or diencephalic damage.

The findings from this study showed that fact memory-that is, the acquisition of new semantic knowledge-was impaired in amnesia. These data therefore create some difficulties for the view that the semantic-episodic distinction can completely describe amnesia. It could be argued, however, that tests of fact memory depend on retrieval of episodic or contextual memory and that control subjects perform better than amnesic patients because they are able to recall episodic memory related to the study session. In this way, it might be argued that impaired fact memory performance in amnesia was actually dependent on a deficit in episodic memory. To reduce the availability of episodic retrieval strategies, we used methods that have been used previously in priming studies: for example, we framed the test session not as a test of previously learned information but as a test of general information, and we never mentioned the previous study session. Moreover, when we tested fact memory, we included at least as many new questions as study questions.

In any case, it is difficult to account for the present findings entirely in terms of a deficit of episodic memory, unless some auxiliary assumptions are added to Tulving's original formulation (Tulving, 1972, 1983). For example, if it is presumed that all memories must be stored in episodic memory before they are stored in semantic memory (Cermak, 1984; Kinsbourne \& Wood, 1982), then fact memory performance is impaired in amnesic patients because of an impairment in episodic memory and not because of an impairment in semantic memory per se. This view, however, does not account for the finding that memory for facts was impaired even when facts were presented prior to the onset of amnesia (Experiment 3), unless the transfer from episodic to semantic memory takes considerable time. Second, this view does not offer an account for entirely normal skill learning and priming in amnesia, unless skill learning and priming are simply defined as examples of semantic memory that do not have to enter episodic memory. If one argues that fact learning requires elements of episodic memory, then the semantic-episodic distinction cannot be easily evaluated empirically (for discussions of related issues, see McKoon, Ratcliff, \& Dell, 1986).

We favor the view that the defining feature of amnesia is an impairment in the ability to establish declarative memory, whereas the ability to establish procedural memory is preserved 
(Cohen, 1984; Cohen \& Squire, 1980; Squire \& Cohen, 1984). The episodic-semantic distinction can be usefully applied to the marked impairment in source memory exhibited by some amnesic patients. This deficit appears to represent a specific and neurologically dissociable impairment in contextual memory. By this view, source amnesia reflects impairment in remembering spatial-temporal context: an impairment in a particular aspect of declarative memory, which can occur in addition to a general impairment of declarative memory. This additional impairment may be related to frontal lobe pathology or to other brain damage, whereas the global deficit in declarative memory (e.g., recall and recognition) in amnesic patients is related to damage to medial temporal and diencephalic brain regions. Thus, the procedural-declarative and episodic-semantic memory distinctions need not be mutually exclusive dichotomies. Both appear to be useful in describing the organization of brain systems.

\section{References}

Baddeley, A. D. (1984). Neuropsychological evidence and the semantic/ episodic distinction. The Behavioral and Brain Sciences, 7, 238-239.

Brooks, D. N., \& Baddeley, A. D. (1976). What can amnesic patients learn? Neuropsychologia, 14, 111-122.

Brown, I. S., Wood, F. B., \& Felton, R. H. (1986). Long term followup of a childhood amnesic syndrome. Society for Neurosciences $A b$ stracts, $12,21$.

Cermak, L. S. (1984). The episodic/semantic distinction in amnesia. In L. R. Squire \& N. Butters (Eds.), The neuropsychology of memory (pp. 55-62). New York: Guilford Press.

Cermak, L. S., Lewis, R., Butters, N., \& Goodglass, H. (1973). Role of verbal mediation in performance of motor tasks by Korsakoff patients. Perceptual and Motor Skills, 37, 259-262.

Cermak, L. S., \& O'Connor, M. (1983). The retrieval capacity of a patient with amnesia due to encephalitis. Neuropsychologia, 21, 213234.

Coblentz, J. M., Mattis, S., Zingesser, L. H., Kasoff, S. S., Wisniewski, H. M., \& Katzman, R. (1973). Presenile dementia: Clinical aspects and evaluation of cerebrospinal fluid dynamics. Archives of Neurology, 29, 299-308.

Cohen, N. J. (1984). Preserved learning capacity in amnesia: Evidence for multiple memory systems. In L. R. Squire \& N. Butters (Eds.), Neuropsychology of memory (pp. 83-103). New York: Guilford Press.

Cohen, N. J., \& Squire, L. R. (1980). Preserved learning and retention of pattern analyzing skill in amnesia: Dissociation of knowing how and knowing that. Science, 210, 207-209.

Cohen, N. J. \& Squire, L. R. (1981). Retrograde amnesia and remote memory impairment. Neuropsychologia, 19, 337-356.

Corkin, S. (1968). Acquisition of motor skill after bilateral medial temporal lobe excision. Neuropsychologia, 6, 225-265.

Crowder, R. G. (1985). On access and the forms of memory. In N. M. Weinberger, J. L. McGaugh, \& G. Lynch (Eds.), Memory systems of the brain. (pp. 433-441). New York: Guilford Press.

Evans, F. J., \& Thorn, W. A. F. (1966). Two types of posthypnotic amnesia: Recall amnesia and source amnesia. The International Journal of Clinical and Experimental Hypnosis, 14, 162-179.

Gabrieli, J. D. E., Cohen, N. J., \& Corkin, S. (1983). Acquisition of semantic and lexical knowledge in amnesia. Society for Neurosciences Abstracts, 9, 28.

Graf, P., \& Schacter, D. L. (1985). Implicit and explicit memory for new associations in normal and amnesic subjects. Journal of Experimental Psychology: Learning, Memory, and Cognition, 11, 501-518.

Graf, P., Squire, L. R., \& Mandler, G. (1984). The information that amnesic patients do not forget. Journal of Experimental Psychology: Learning, Memory, and Cognition. 10, 164-178.

Hirst, W. (1982). The amnesic syndrome: Descriptions and explanations. Psychological Bulletin, 91, 435-460.

Huppert, F. A., \& Piercy, M. (1978). The role of trace strength in recency and frequency judgements by amnesic and control subjects. Quarterly Journal of Experimental Psychology, 30, 346-354.

Jacoby, L. L., \& Witherspoon, D. (1982). Remembering without awareness. Canadian Journal of Psychology, 32, 300-324.

Kaushall, P. I., Zetin, M., \& Squire, L. R. (1981). A psychosocial study of chronic, circumscribed amnesia. Journal of Nervous and Mental Disease, 169, 383-389.

Kinsbourne, M., \& Wood, F. (1975). Short-term memory processes and the amnesic syndrome. In D. Deutsch \& J. A. Deutsch (Eds.), Shortterm memory (pp. 258-291). New York: Academic Press.

Kinsbourne, M., \& Wood, F. (1982). Theoretical considerations regarding the episodic-semantic memory distinction. In L. S. Cermak (Ed.), Human memory and amnesia (pp. 195-217). Hillsdale, NJ: Erlbaum.

Mair, W. G. P., Warrington, E. K., \& Weiskrantz, L. (1979). Memory disorder in Korsakoff psychosis: A neuropathological and neuropsychological investigation of two cases. Brain, 102, 749-783.

Mayes, A. R., Meudell, P. R., \& Pickering, A. (1985). Is organic amnesia caused by a selective deficit in remembering contextual information? Cortex, 2I, 167-202.

McKoon, G., Ratcliff, R., \& Dell, G. S. (1986). A critical evaluation of the semantic-episodic distinction. Journal of Experimental Psychology: Learning, Memory, and Cognition, 12, 295-306.

Milner, B. (1962). Les troubles de la memoire accompagnant des lesions hippocamiques bilaterales [Memory impairment associated with bilateral hippocampal lesions]. In Physiologie de l'hippocampe [Cognitive processes and the brain] (pp. 257-272). Paris: Centre National de la Recherche Scientifique.

Milner, B., \& Petrides, M. (1984). Behavioural effects of frontal-lobe lesions in man. Trends in Neuroscience, 7, 403-407.

Mishkin, M. (1982). A memory system in the monkey. Philosophical Transactions of the Royal Society, 298, 85-95.

Nelson, T. O., \& MacLeod, C. M. (1974). Fluctuations in recall across successive test trials. Memory \& Cognition, 2, 687-690.

Nelson, T. O., \& Narens, L. (1980). Norms of 300 general-information questions: Accuracy of recall, latency of recall, and feeling-of-knowing ratings. Journal of Verbal Learning and Verbal Behavior, 19. 338-368.

Ostergaard, A. L. (in press). Episodic, semantic and procedural memory in a case of amnesia at an early age. Neuropsychologia.

Price, T. R. P. (1982). Short- and long-term cognitive effects of ECT: Part 1-effects on memory. Psychopharmacology Bulletin, 18, 81-91.

Schacter, D. L. (1986). Memory, amnesia, and frontal lobe dysfunction: A critique and interpretation. Manuscript submitted for publication.

Schacter, D. L., Harbluk, J. L., \& McLachlan, D. R. (1984). Retrieval without recollection: An experimental analysis of source amnesia. Journal of Verbal Learning and Verbal Behavior, 23, 593-611.

Schacter, D. L., \& Tulving, E. (1982). Memory, amnesia, and the episodic/semantic distinction. In R. L. Isaacson \& N. E. Spear (Eds.), Expression of knowledge (33-65). New York: Plenum Press.

Shimamura, A. P. (1986). Priming effects in amnesia: Evidence for a dissociable memory function. Quarterly Journal of Experimental Psychology. 38A, 619-644.

Shimamura, A. P., \& Squire, L. R. (1984). Paired-associate learning and priming effects in amnesia: A neuropsychological study. Journal of Experimental Psychology: General, 113, 556-570.

Shimamura, A. P., \& Squire, L. R. (1986). Memory and metamemory: A study of the feeling-of-knowing phenomenon in amnesic patients. 
Journal of Experimental Psychology: Learning, Memory, and Cognition, 12, 452-460.

Squire, L. R. (1982). Comparisons between forms of amnesia: Some deficits are unique to Korsakof's syndrome. Journal of Experimental Psychology: Learning. Memory, and Cognition. 8. 560-571.

Squire, L. R. (1984). ECT and memory dysfunction. In B. Lerer, R. D. Weiner, \& R. H. Belmaker (Eds.), ECT: Basic mechanisms (pp. 156163). London: John Libbey.

Squire, L. R. (1987). Memory and brain. New York: Oxford University Press.

Squire, L. R., \& Cohen, N. J. (1984). Human memory and amnesia. In G. Lynch, J. L. McGaugh, \& N. M. Weinberger (Eds.), Neurobiology of learning and memory (pp. 3-64). New York: Guilford Press.

Squire, L. R., Cohen, N. J., \& Zouzounis, J. A. (1984). Preserved memory in retrograde amnesia: sparing of a recently acquired skill. Neuropsychologia, 22, 145-152.

Squire, L. R., \& Shimamura, A. P. (1986). Characterizing amnesic patients for neurobehavioral study. Behavioral Neuroscience, 100, 866877.

Squire, L. R., Slater, P. C., \& Chace, P. M. (1975). Retrograde amnesia: Temporal gradient in very long-term memory following electroconvulsive therapy. Science, $187,77-79$.

Squire, L. R., \& Zola-Morgan, S. (1983). The neurology of memory:
The case for correspondence between the findings for human and nonhuman primates. In J. A. Deutsch (Ed.), The physiological basis of memory (2nd ed., pp. 199-268). New York: Academic Press.

Teuber, H. L., Milner, B., \& Vaughan, H. C. (1968). Persistent anterograde amnesia after stab wound of the basal brain. Neuropsychologia, 6, 267-282.

Tulving, E. (1967). The effects of presentation and recall of material in free-recall learning. Journal of Verbal Learning and Verbal Behavior. $6,175-184$.

Tulving, E. (1972). Episodic and semantic memory. In E. Tulving \& W. Donaldson (Eds.), Organization of memory (pp. 381-403). New York: Academic Press.

Tulving, E. (1983). Elements of episodic memory: Oxford: Clarendon Press.

Tulving, E. (1986). What kind of a hypothesis is the distinction between episodic and semantic memory? Journal of Experimental Psychology: Learning, Memory, and Cognition, 12, 307-311.

Wood, F., Ebert, V., \& Kinsbourne, M. (1982). The episodic-semantic memory distinction in memory and amnesia: Clinical and experimental observations. In L. S. Cermak (Ed.), Human memory and amnesia (pp. 167-194). Hillsdale, NJ: Erlbaum.

Received February 26, 1986

Revision received July 31, 1986 